\title{
Sink or Swim: Teachers' Stress Coping Mechanisms in a South African School
}

\author{
Sybert Mutereko \\ School of Education, University of KwaZulu-Natal, South Africa \\ Email: Sybert@ukzn.ac.za \\ Pepukayi Chitakunye \\ University of the Witwatersrand, Faculty of Commerce, Law and Management \\ Email: pepukayi.chitakunye@wits.ac.za
}

Doi:10.5901/mjss.2014.v5n27p698

\begin{abstract}
This article explores the causes and nature of coping mechanisms designed to survive stress experienced during the implementation phase of the National Curriculum Statements (NCS) policy by teachers in South Africa. A discussion is presented of prior research documenting working conditions of teachers and other street-level bureaucrats in other countries. These analyses suggest that there is a dearth of literature on this topic in the African context. A mixed methods approach is used to explicate the emic teacher coping mechanisms that arise in the normalcy of everyday life. Insights are drawn from indepth interviews (5), observation (65 days), survey (26) and 25 pages of detailed field notes, to explore the nature of coping mechanisms designed by teachers. The findings demonstrate that stress among teachers during NCS policy implementation emanate from scarcity of resources, goals and performance measures and relations with non-voluntary clients. In turn, teachers adopt coping mechanisms such as creaming, rubber stamping, referral, modifying the conception of work, private goal definition and withdrawal, which might affect the attainment of policy goals as teachers end up adapting the curriculum policy rather than implementing it as it is.
\end{abstract}

Keywords: street-level bureaucrats, stress, coping mechanisms, scarcity of resources, discretion, policy enactment

\section{Introduction}

Policy implementation scholars and practitioners have noted an increased need to understand why policies achieve or do not achieve the desired results (Beukes 2008; Exworthy et al., 2002). One prominent explanation to this dilemma is the coping mechanisms employed by front-line workers (or street-level bureaucrats) during implementation (Lipsky 2010, 1980; Taylor 2007). Street-level bureaucrats (such as teachers) often operate under duress from acute shortage of recourses, an ever-increasing demand for their services which out-strip supply, poor clarity of organisational goals, performance goals which are ever shifting, and the non-voluntary nature of their clients (Lipsky 2010). The upshot of this is that front-line workers use their discretion and autonomy from management to devise coping mechanisms which enable them to survive the pressure. In some cases, coping mechanisms are designed to make teachers' work comfortable, and to enable teachers to manage the stress that is brought by pressure of work while, in other cases, such coping strategies are earnestly meant to aid policy implementation. Further to this, street-level bureaucrats make policies from 'the bottom' through the exercise of their discretion and autonomy (Lipsky 2010). Public administrators are ambivalent to the use of coping mechanism as on the one hand, they fear that such coping mechanisms are designed to make the front-line workers' work more comfortable, at the expense of the organizational goals. On the other hand, some public managers perceive such coping mechanisms as intended to achieve organizational goals and assist clients.

The role of teachers' coping mechanisms in policy implementation has remained a principal theme in policy implementation discourse (Tummers and Bekkers 2014; Smith 2012; Johnsson 2012; Grimaldi 2012; Aldridge et al., 2006). This is underpinned by the need to gain a comprehensive insight into the nature and cause of such coping strategies, as it influences the efficacy of organisation and, by extension, the effectiveness of government to deliver services. Such an understanding could hypothetically lead to better management of front-line workers, help policy-makers and aid to analytic lenses used to investigate the street-level workers.

Since Lipsky's (1980) seminal work, several scholars have attempted to shed more light on the discourse of frontline workers' coping mechanisms in policy implementation through empirical studies (Tummers and Bekkers 2014; 
Smith 2012; Johnsson 2012; Richards 2012; Mansfield et al., 2012; Aldridge et al., 2006). Smith who was studying coping mechanisms among teachers, reports that most of them distanced themselves from stressful situations where possible or adopted confrontive actions to face the pressures and stressors (Smith 2012). Other coping mechanisms identified include problem-solving, help-seeking skills, ability to accept failure and dependence on social support networks (Mansfield et al., 2012). Some scholars classify teachers' mechanisms as personal coping mechanisms, professional coping mechanisms, social coping mechanisms and institutional coping mechanism (Murray-Harvey et al., 2010) while some group them into three broad categories: client control, job conceptualisation and client conceptualisation (Johnsson 2012). These understandings will help to inform the current study.

Whilst we know much about coping mechanisms among front-line workers in the Western world, we know less about insights surrounding this topic from an African context. This is despite Lipsky's (1980; 2010) assertion that the exercise of discretion and coping mechanisms during policy enactment are underpinned by the socio-cultural environment of concerned street-level bureaucrats. Previous studies have mostly focused on the coping mechanisms of street-level bureaucrats in developed nations. Consequently, the behaviour and nature of coping mechanism is not well understood. Our knowledge concerning the coping mechanisms of street-level bureaucrats in South Africa is largely based on understandings and data sets generated in the Western world.

It is against this backdrop that we undertook this study to investigate how teachers at a school in South Africa cope with the pressure that comes with their work in the implementation of National Curriculum Statements (NCS). Our research approach places more emphasis on phenomenological meanings, to more fully understand the coping strategies used by teachers in everyday school life. Little research has focused on the meanings that the coping strategies assume in the world of school teachers. From this interpretive orientation, two important questions remain unaddressed by the existing literature: (1) what are the meanings embedded in coping mechanisms that are devised by the teachers, and (2) what coping mechanisms are adopted by teachers in the course of the work? As will be shown in the emically focused analysis, the exploration of these questions offers a deeper understanding that highlights the embedded meanings in stress coping strategies adopted by teachers.

The paper commences with a review of the literature surrounding coping mechanisms, in order to lay the theoretical foundations of the study. This section will be divided into two: causes of coping mechanisms (stressors); and coping mechanisms adopted by teachers.

\section{Why do Street-Level Bureaucrats Employ Coping Mechanisms?}

We begin our investigation of coping mechanisms among school teachers by drawing insights from the theory of streetlevel bureaucracy (Lipsky 2010 1980). According to this theory, there are three main issues that are at the centre of causing conflicts (and stress) in street-level organisations which call for the adoption of coping mechanisms from frontline workers implementing public policies (Tummers and Bekkers 2013; Lipsky 2010, 1980). These are (1) the problem of resources, (2) goals and performance measures and (3) relations with clients. Lipsky (2010) and Keddie (2013) summarise these as the conditions of work, or school context. Each of these factors will be discussed in turn.

\subsection{Scarcity of resources}

Concerning the problem of resources, Lipsky (2010) emphasises that street-level bureaucrats are expected to perform to their optimum levels with inadequate resources at their disposal. With reference to resources, Lipsky classifies them into theoretical, practical and personal resources. Time and information are regarded as resources that are required by streetlevel bureaucrats in order to execute their tasks effectively. And yet they are always in short supply. Because of high work-load and the need to make urgent decisions concerning their clients, they may often act without investing in searching for more information (Maphalala 2014; Lipsky 2010). Street-level bureaucrats often fear that not making such haste in the presence of clients would be interpreted as incompetence, or lack of authority, which may attract negative reactions from both management and clients.

Recent studies confirm Lipsky's $(2010 ; 1980)$ assertions on effect of scarcity of time resources in the implementation of educational policy (Maphalala 2014; Aldridge et al., 2006:60). For instance, teachers rarely engage their learners in group activities because such activities consume a lot of time. Regarding the scarcity of time resources, one teacher gave them this response:

Considering the available time at my disposal [30 min per lesson], I feel that I won't be able to do justice to group work. Hence I decided to leave [the students] seated as they are. [...] The length of my period is short and I think that, if students are to sit in groups, this is going to waste much of my time. [...] Maybe, if the period length is changed, I will 
consider forming permanent groups (Aldridge et al., 2006, 60).

In this, the teacher was referring to the seating arrangement of the learners which reflected traditional rows at tables facing the teacher and chalkboard 'in front'. In the face of inadequate time, this teacher finds it time-consuming to change the seating arrangement repeatedly.

Turning to practical resources, street-level bureaucrats work with fewer resources than they need (Mogashoa 2013). For instance, teachers are often overwhelmed by high teacher student ratios, which hinder effective teaching, as most of the time will be spent maintaining order (Lipsky 2010). Consonant with this is the constant fear of physical assault by students, which increases the level of stress among teachers due to poor discipline (Crossman and Harris 2006). There is also the amount of time teachers spend doing housekeeping chores such as drawing up of year plans, terms plans and lesson plans, which affect the amount of time available for their clients (Maphalala 2014; Lipsky 2010). Other studies that emerged after Lipsky (1980) confirm that resources are a major challenge for school teachers. In the South African context, most teachers face a critical shortage of resources (Aldridge et al., 2006; Deventer 2009). For instance, life orientation teachers reported that they did not have sufficient facilities and equipment to offer Physical Education, Sport and Recreation (Deventer 2009,141) while Aldridge et al. $(2006,64)$ report that due to the shortage of text books teachers resorted to lecturing. Teachers argued that '... for them to be in charge of their learning process, they need to have the learning materials, which they don't because they are sharing text-books' (Harden 2002, 151; Department of Education 2003, 9). In such situations, teachers need to devise coping mechanisms and use their discretion to implement policy.

With regard to personal resources, Lipsky (2010) draws our attention to the lack of skills, knowledge and competence among frontline workers. This could be a result of inexperience or poor training. Such workers are often stressed and frustrated when they fail to perform their jobs. This is so even when the failure is attributable to the nature of their job, rather than rooted in their personal failure. A sense of efficacy is an important personal resource among teachers. A recent review of the literature on this topic found that the absence of a sense of efficacy (i.e. realised when individual workers are confident enough to master organisational objectives) can lead to pressure and burnout among teachers and even school principals (Reames et al., 2013; Sharplin et al., 2011; Fantilli and McDougall 2009; Nayak 2008). This sense of efficacy is often a result of effective training and experience.

Taken together, scarcity of resources in bureaucratic organisations often forces teachers to engage in survival behaviours or coping mechanism which might affect the enactment of curriculum policy. In some cases, this is done in an effort to advance the cause of their clients or achieve organisational goals (Winter 2002).

\subsection{Goals and performance measures}

Ambiguous, conflicting and vague organisational objectives are another critical source of stressors and pressure among frontline workers implementing curriculum policy (Lipsky 2010; Thomson 2008). The pace at which new ideas in education are coming has a direct impact on educational policy strategies and goals. Policy-makers are constantly reviewing their policies and goals in light of new knowledge. These changes create pressure on the workforce because they have to change their practice during policy enactment (Makeleni and Sethusha 2014). In that sense, policy goals in bureaucracies are 'more like receding horizons than fixed targets' (Lipsky 2010, 40).

However, a growing number of studies on the stressors that force front-line workers to devise coping mechanisms fail to take cognisance of the ambiguity of organisational goals as one of such causes of coping mechanisms (Maphalala 2014; Richards 2012; Sprenger 2011). Contrary to Lipsky's (2010) views, Sprenger (2011) suggests that it is in fact the pressure and distraction from other stressors that derail teachers from educational goals. Although this is not supported by empirical evidence, Parsons (1995) underscores the policy goals to avoid confusion among the workers.

Performance measures have generated enormous pressure on street-level bureaucrats (Thomson 2008). This stems from the nature of work, which cannot be measured through measures of profitability. Lipsky $(1980,49)$ notes that problems in measuring the performance are 'endemic in street-level bureaucrats' work'. This is because, for instance, educational goals such as 'developing a respectful citizenry', are ephemeral and difficult to operationalise. This is confounded by a multiplicity of goals that may need to be measured: pass rates, number of lessons, maintenance of discipline and creating a conducive learning atmosphere. Street-level bureaucrats are often confused and stressed when faced with such challenges. For instance, a study by Butler (2007) reveals that in-as-much as students are striving for higher scores, teachers are determined to score higher in performance evaluation. Similarly, in California, Richards (2012) notes that the situation was made worse by increased budgetary constraints. 


\subsection{Relations with non-voluntary clients}

Lipsky (2010) identifies the non-voluntary nature of the learners as one primary source of stressors during curriculum policy enactment, which calls for coping mechanisms. The non-voluntary nature of clients has an implication on the quality of, for instance, teachers and learners. Teachers require a certain degree of compliance for them to successfully deliver the services. Failing to secure compliance can result in frustration and stress among workers. Compliance from their learners is crucial for effective learning. With this in mind, teachers often devise coping strategies to improve the quality of their interaction with learners.

Recent studies have used empirical data to demonstrate how the relations with non-voluntary clients pose a serious source of stressors for teachers enacting curriculum policy (Maphalala 2014; Richards 2012; Smith 2012; Sprenger 2011; Fantili and McDougall 2009). Lack of motivation, student apathy and poor attendance, which is coupled with discipline problems, was a common finding among these authors (Crossman and Harris 2006). Often, teachers spend the bulk of their teaching time in trying to enforce discipline. In a study carried out by Richards $(2012,56)$ one respondent remarked:

\section{'...how we feel about education doesn't matter. ... I feel like I shovel the curriculum down student's throats, instead of acting as a facilitator in their learning...'}

Such a challenge calls for teachers to develop effective coping mechanisms if they were to stay in the profession or achieve the set educational goals.

Broadly, Lipsky views these three factors as the main sources of stress among street-level bureaucrats during enactment of curriculum policy which call for coping mechanisms. Although street-level bureaucrats are subjected to similar stressors in their organisations, they devise coping mechanism as individuals. Which coping mechanisms do teachers employ? The next section addresses this question.

\subsection{Coping mechanisms}

Coping mechanisms adopted by teachers in the course of implementing educational policies are varied but can be broadly classified into four types: personal coping mechanisms, professional coping mechanisms, social coping mechanisms and institutional coping mechanism (Murray-Harvey et al., 2010). Personal coping mechanisms are attempts by teachers to focus on the positive side of their challenges and conditions of work (Brackenreed 2011; Murray-Harvey et al., 2010). These involve knowing the nature of the work and understand one's capacity in order to set realistic goals that are attainable. Richards' (2012) study reveals that most teachers in California tend to have a positive attitude, no matter what goes on in their work situations. These are attitudinal coping responses (Lipsky 2010).

With regard to professional coping mechanism, scholars agree that teachers cope with their work conditions and stress by being well-organised in terms of preparation and planning, mastering pedagogic, as well as content knowledge of their subjects, which lead to planned problem-solving (Yeung 2012; Brackenreed 2011). Some scholars contend that such professional skills, attitude and intellect is realised after a lengthy process of professional socialisation of teachers (Sharplin et al., 2011). With regard to social coping mechanisms, researchers have found that teachers often talk about their problems with family and friends and reflect on their situations as a coping mechanism (Hawk and Martin 2011; Murray-Harvey et al., 2010).

Turning to institutional coping mechanisms, studies discuss the importance of talking to colleagues, supervisors and other formal structures within the school about specific problems as a common coping mechanism among educators (Brackenreed 2011; Murray-Harvey et al., 2010). Such a strategy gave the teachers an opportunity to share common experiences and solutions.

Previous research identifies several coping strategies, which include (1) 'creaming', (2) 'rubber stamping', (3) referrals, (4) working overtime and modifying the conception of work, (5) private goal definition and (5) withdrawal (Lispky 2010). Such studies fail to explain the impacts of coping mechanism on the implementation of educational policy. Such scholarship is void of African context. As a consequence, our understanding of coping mechanisms in South Africa is largely based on unsubstantiated assumptions. It is our contention that the current paper is an important step towards filling that gap in scholarship. 


\section{Methodology and Methods}

This article emerged from a larger study, which applied Lipsky's (1980) street-level bureaucracy theoretical lenses to gain insight into the teachers' discretionary practices during policy enactment using The foci of the current paper were twofold: (1) to investigate the causes of coping behaviour among teachers and (2) to explore the nature of coping mechanisms deployed by teachers in the course of enacting educational policy. For this paper, the setting we have chosen for this exploratory study is a combined school (from Grade R to Grade 12) in Pietermaritzburg in South Africa. The research team comprised two qualified school teachers. The first author conducted all the fieldwork. His role as a teacher at this combined school privileged his access to discussions surrounding policy implementation, and access to study informants. As in Crockett and Wallendorf (2004), the second author provided analytical distance in both coding and analysis.

This study adopted a mixed methods approach. Multiple data sources were deployed to produce a deeper understanding of the everydayness of policy issues within the context of the school, and to capture those practices that are often taken for granted in most accounts of policy formulation and implementation. The multiple data sets allowed for different models of reality to emerge. These sources are illustrated in Table 1.

Table 1. Methods of data collection

\begin{tabular}{ll}
\hline Data collection method & Quantity \\
\hline School-based observations & 65 days (Monday to Friday) \\
Field notes & 25 printed ages (A4) \\
In-depth interviews & 5 participants \\
Survey & 26 participants \\
\hline
\end{tabular}

Here, qualitative data was collected by observation of teachers' daily activities for 65 days. Observations at the school were vital in deepening our experience of teachers within this particular school. The focus of the observations was on the teachers implementing the NCS. Insights from the observations were analysed before going on to conduct the interviews. We adopted an overt role and made our presence and intentions known to the group.

The survey method was used to collect the quantitative data. Insights from the qualitative data sources were used to develop a questionnaire to gather insights from 26 teachers out of the 32 at that school, to allow for the generalizability of the results to the study site. The questionnaires were distributed to 26 conveniently recruited teachers who agreed to take part in the study. Questionnaires were administered in a personal interviewing format, with each interview lasting approximately one hour, and responses were recorded verbatim. The questionnaires included closed questions and a space for open-ended comments. The space for open-ended comments allowed the interviewees a degree of freedom to explain their thoughts and highlight special areas in which they exercise discretion in the implementation of the NCS and to allow certain responses to be questioned in greater depth.

Prior to, during, and subsequent to, our immersion in the school environment, we kept detailed written fieldnotes, amounting to 25 A4 typed pages. Qualitative interviews were tape-recorded and then transcribed for analysis. Interview transcripts were read in detail several times and analysed following the principles for the analysis and interpretation of qualitative data (Spiggle, 1994). The analysis continued in an iterative fashion across all the data sources (Chitakunye and Maclaran, 2012). Frequency tables and bar graphs were used to present summary statistics. Cross-tabulation was used to explore relationships in the data. This choice has been made because cross tables are easy to understand and they also appeal to people who do not want to use more sophisticated measures. Using Lipsky's street-level bureaucracy theory as analytical tools provided us with realistic and valid descriptions of the causes and nature of coping behaviour among the teachers.

\section{Results and Discussion}

The emic meanings of coping mechanisms during enactment of curriculum policy are presented in terms of four interrelated thematic dimensions, namely, scarcity of resources; clarity of goals and performance measures; and relationship with non-voluntary clients. The nature of coping mechanisms deployed by teachers is presented in the last subsection. 


\subsection{Scarcity of resources}

Our findings reveal that some of the teachers complained about the workload and the resources available. On a scale of 1 to 5 , with 1 being the lowest and 5 being the highest, $69.9 \%$ of the teachers were at 3, which meant that resources were adequate to some extent. Only $3.8 \%$ said the resources were not adequate at all. Some of those who complained are Physical Education teachers, who said they do not have enough facilities and equipment. For instance, they do not have a swimming pool and a proper soccer pitch. Because of that, they say they spent a lot of teaching time on travelling to hired grounds and swimming pools. Another group of teachers reported that they do not have whiteboards and enough computers that are connected to the internet. Few teachers (3.8\%) said the resources were adequate, to a 'very great extent'. One teacher complained:

We need more resources than we get. We need more charts, we need CD players, radios, we need overhead projectors, and there are times when you say need stuff and they tell there is no money for that. You know, we want to be creative in classrooms but you can't be really creative because you don't have the resources (Tr18).

This theme highlights the focal meanings and experiences that participants expressed towards the scarcity of resources within the school. Our observation shows that resources at this school were generally inadequate. It emerged that a shortage of resources forced the teachers to improvise and use their discretion in order to cope. Figure 1 illustrates the responses of teachers when asked about the adequacy of the resources in the implementation of the NCS.

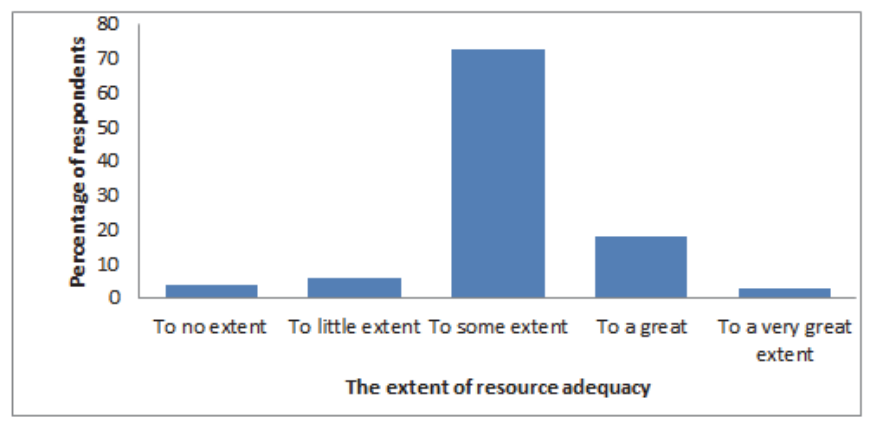

Figure 1. Adequacy of resources

Our findings indicate that the shortage of resources included shortage of manpower, which translated into a heavy workload for the few educators. Figure 2 illustrates the responses of teachers when they were asked about their workload.

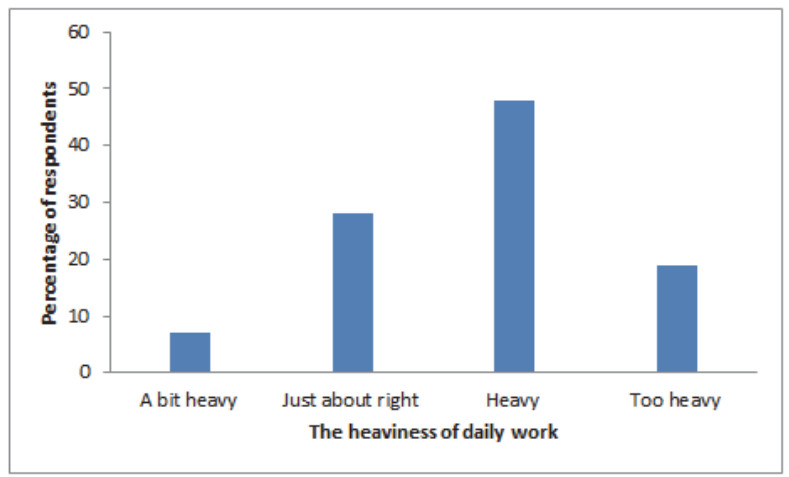

Figure 2. Daily workload in implementing NCS

Because of the workload and other factors, some teachers complained that this is making their job very difficult. For instance, only $7.7 \%$ of the teachers said their job is a 'bit light' and $26.2 \%$ said their job is 'just about right'. Most of these are either part-time or assistant teachers; $46 \%$ of the teachers said their job was heavy, while $19.2 \%$ said the job was too 
heavy for them. Most teachers complained about administrative work, which takes up large proportion of their time. The same work is demanded by the Department of Education and the school management in two different formats. As a result, much of the teachers' time is spent doing these administrative tasks instead of teaching, making the teachers' work very onerous.

It emerged that teachers teach across a number of subjects which have different learning outcomes and assessment standards. Each subject has its own administrative and clerical work. For example, Tr8 said:

'...all I want about teaching is teaching the learners and not much about administration...' (Tr8).

Our study found that time was another critical resource that was in short supply. This factor forces teachers to use discretion in order to do all their work in the limited time. Our findings indicate that the majority of teachers (46.2\%) spent 61 to $80 \%$ of their working day in the class with the learners, while only one teacher (3.8\%) spent less that $20 \%$ of the day with the learners.

There was a difference between the percentage of time that is devoted to face-to-face tuition between respondents who were full-time and some who are part-time. Part-time teachers spend less time with the learners than the full-time teachers do. It follows that if a teacher spends 61 to $80 \%$ of the time with the learners, only $20 \%$ of the time left is for administration work. Many teachers complained that this is not enough time. To cope with this, teachers use their discretion. One respondent said that:

With time and experience you develop techniques around this problem. You use short cuts (Tr25).

The use of 'short cuts' entails the use of professional discretion by the teachers as a way of coping with the pressure that comes with implementing the NCS. In many cases, this involves window dressing and doing what is comfortable for the teacher and the learners. This is reinforced by Tr18, who had this to say:

You cannot do everything that is required by the policy. I only do what I can. (Tr18).

This is consistent with our observations. At certain times of the term, it was observed that teachers work after hours and during weekends. Our study empirically validates the assertion that scarcity of resources in schools is a major cause of stress among teachers. The findings are barely distinguishable from Lipsky (2010) and Aldridge et al. (2006), who identified such scarcity as a major factor which compels educators to devise coping mechanisms. Aldridge (2006) reports that, in order to save time teachers often shun teaching methods that they think consume a lot of time and resort to the lecture method. In terms of practical resources, Deventer $(2009,141)$ reports that Life Orientation teachers in South Africa reported that they did not have sufficient facilities and equipment to offer Physical Education and Sport and Recreation. Lipsky (2010) argues that lack of personal resources (proper training and experience) among newly qualified teachers lead to increased stress and the devising of coping mechanisms.

\subsection{Clarity of goals and performance measures}

Another factor which forces street-level bureaucrats to use discretion in order to cope with their work conditions is related to the clarity of goals and performance measures in the NCS policy. Our study sought to find out whether the goals are clear, specific and reasonable. In responding to the reasonability of NCS goals, TR4 stated:

Some of the Department's requirements are unpragmatic... if you want to know how unpragmatic they are... I got a fax today saying I must bring my Physical Education tasks for moderation and I need to bring my best learner, middle learner and the worst learner so that they can be moderated. However, according to assessment standards and the learning outcomes, my task was a hike on the mountain and the other one was carrying poles over the football goals, so how am I going to carry the 'mountain and the best learners and the worst learners' for moderation... absolutely unpragmatic (Tr4).

On the issue of clarity, $46.9 \%$ of the respondents said the goals of the NCS are clear 'to some extent', which meant level four on a scale of 1-5, with five being very clear; $11.5 \%$ indicated that policy goals are clear 'to a little extent' (level 2). Only $7.7 \%$ of the respondents said the policy goals are very clear in stating what should be done by the teachers and supervisors. Although some respondents said the objectives and requirements are clear, they also said some of the requirements are not reasonable (Tr4).

In addition to the above, our study asked the respondents to rate the policy goals on the level of specification with 
level 1 (very general) and 5 (very specific). A larger proportion (26.9\%) of respondents said policy directives were very specific (level 5). Only one respondent (3.8\%) said the policy was very general (level 1). The understanding of whether a policy is general or specific is critical in policy implementation. This allows room for discretion when the policy directives are very general and the reverse is true when they very are specific. Figure 3 shows the response of teachers on the way they understand the policy goals in terms of clarity.

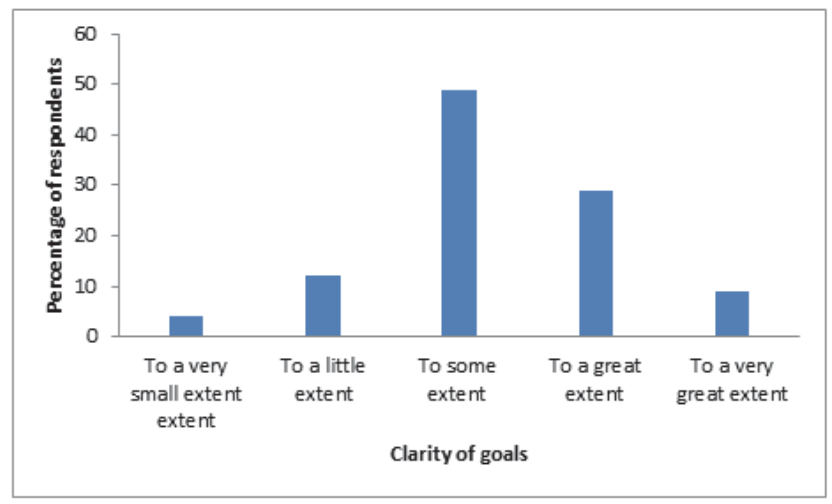

Figure 3. Extent of the clarity of goals

When policy goals are not clear and specific, it is difficult for street-level bureaucrats to implement the policy correctly. In connection with this, one teacher said:

'...some of the terms used in the policy are difficult to understand. There is a word in the Arts and Culture Learning Area Statement that I don't even know the meaning of. The word is not in the dictionary...' (Tr3).

Most frontline workers lack confidence in what they do, particularly when they do not understand what the policy requires of them; $42.3 \%$ of the respondents indicated that it is 'quite easy' for them to tell that they have done their work correctly with $7.7 \%$ saying it is very easy for them to tell that they have done their work correctly, Table 2 shows the responses of teachers when they were asked how easy or difficult it is to be sure that they have done their work correctly. Although a small proportion (19.2\%) of the respondents said it is 'quite difficult' to be sure that they have done their work, it is important to note that this is a significant proportion.

Table 2. Extent to which they know they have done work correctly

\begin{tabular}{lccc}
\hline & Frequency & Percent & Cumulative Percent \\
\hline Very difficult & 1 & 3.8 & 3.8 \\
Quite difficult & 5 & 19.2 & 23.1 \\
Somewhat difficult & 7 & 26.9 & 50.0 \\
Quite easy & 11 & 42.3 & 92.3 \\
Very easy & 2 & 7.7 & 100.0 \\
\hline $\mathrm{n}=26$ & & &
\end{tabular}

Table 2 indicates that a small proportion (7.7\%) of the teachers is sure that they have done their work correctly, about 41$100 \%$ of their working time. The same percentage (19.2\%) who said it was difficult for them to be sure that they have done their work correctly also said they are only sure that they have done their work correctly less than $20 \%$ of the time. In was interesting to note that $42.3 \%$ of the teachers indicated that it was 'quite easy' for them to tell that they have done their work correctly.

Although our findings confirm Lipsky's (2010) claims on the effect of ambiguity of goals and performance measures on causing stress and coping mechanisms among teachers, they do not support previous research in this area. In fact, contrary to what was previously thought, we found that at least $46.9 \%$ of respondents were satisfied with the policy goals. Our findings substantiate Sprenger's (2011) suggestion that it is, in fact, the pressure and distraction from other stressors that derail teachers from educational goals. 


\subsection{Relations with non-voluntary clients}

All the teachers complained about the attitude of learners towards education. They noted that this was one major area which brought them stress every day. Some educators made the following comments concerning the non-voluntary nature of learners as a source of stress.

\footnotetext{
'...If there is anything that stresses me in being a teacher, it is the attitude of learners towards their education...' (Tr16) '...Some learners told me that if they failed their examinations it is my problem as a teacher. Those learners told me that learners should not work very much but the teachers...'(Tr20)

'...The NCS requires that some of the assessments must be done as projects at home. Collecting such assessments from learners for marking is a nightmare...' (Tr12)
}

For these participants, maintaining discipline in their classes was taking up a significant proportion of their time. This was a common paradox that arose in the interviews. This problem was made worse by the national legislation on how teachers should treat learners in terms of what they say to them, verbally or otherwise.

As raised by Lipsky (2010), the evidence we found confirms that the relations with non-voluntary clients are a major source of stress among teachers. This problem is often manifested in poor discipline, lack of motivation and poor attitudes towards school work by learners and it causes educators to devise coping mechanisms. These findings are consistent with the literature (Richards 2012; Smith 2012; Sprenger 2011; Fantili and McDougall 2009). For instance, in a study of stressors among teachers in California, Richards (2012) reports that respondents felt as if they were forcing learners to learn.

\subsection{Which coping mechanisms do teachers use?}

Our study identified six broad themes that emerged as broad classes of coping by educators in order to survive their conditions of work. These are presented here.

\subsubsection{Creaming of the faster and obedient learners}

Our study sought to reveal how the teachers cope with their workload in the implementation of the NCS. Many teachers complained about workload. One teacher said:

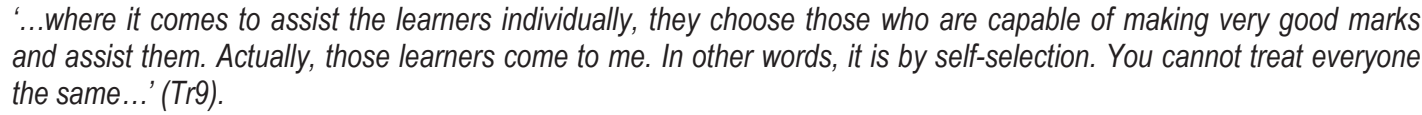
and assist them. Actually, those learners come to me. In other words, it is by self-selection. You cannot treat everyone the same...' (Tr9).

This is what Lipsky $(1980,107)$ says when street-level bureaucrats are confronted by more clients than can readily be accommodated. They often choose (or skim off the top) those who seem mostly likely to succeed in terms of the criteria of bureaucracy. This happens despite the formal requirement by the policy to treat learners equitably. In Lipsky's terms, this is called 'creaming' $(1980,107)$.

Another way in which teachers are practising creaming is by choosing those learners with special needs, or who are slow in grasping some concepts and giving them special attention. For instance, Tr1 and Tr6 have a special programme for learners with isizulu language problems. Every Friday, they offer remedial lessons to those learners for a period of one hour. Lipsky $(1980,107)$ calls this a form of creaming in which clients who are at 'high risk' are selected.

\subsubsection{Rubber stamping}

Most teachers also cope with the pressure of their work by 'rubber stamping', because they do not do baseline assessment, as required by the policy. They said that there is a promotional requirement from each grade or phase to the next. If a learner does not meet this requirement he or she does not proceed to the next grade or phase. In that case, what is the purpose of doing baseline assessment? Lipsky says teachers use the judgements of children's previous teachers in their informal assignments as early as the second grade. Rubber stamping also happens in peer moderation assessment tasks, which are given little attention by teachers. In this case teachers endorse or 'rubber stamp' the judgements made by the previous teachers $(1980,129)$.

In response to increased workload, respondents indicated that they do not give full attention to the work that has 
already been done by a colleague. This often happens during peer moderation, where teachers simply rubber stamp. These findings substantiate Lipsky's (2010) assertion that rubber stamping is a mechanism of coping with work conditions.

\subsubsection{Referral of stressful cases}

It was observed that, in some cases where children needed special attention, teachers referred difficult or problem cases to other people employed in the organisation or to other organisations. For instance, teachers refer some disciplinary cases to phase co-ordinators and at times to the school management. According to Lipsky $(1980,133)$, this usually happens when novices as supervisors ask more experienced workers to handle clients who present difficulties. This coping mechanism arises not because cases defy a teacher's ability to handle them, but because they interfere with routine procedures in class.

It also emerged that teachers 'develop sanctions to punish disrespect to routines of order' (Lipsky 1980, 125). Many teachers reported that at times they send children for detention if the children commit 'educational sins'. In concurrence with Lipsky's assertion that 'teachers in traditional schools fear the removal of sanctions that, rightly or wrongly, they believe to be effective deterrents to student misconduct' (Lipsky 1980, 125), teachers complained that the banning of corporal punishment in schools is making their job difficult. Most teachers agreed that the current forms of punishment may not be effective. This is captured in the following statement:

\footnotetext{
'...the position of this school as a biblically-based school is compromised when corporal punishment is removed from schools...' (Tr7).
}

Our findings suggest that teachers referred job tasks that they thought were beyond their capacity as a way of coping. Brackenreed (2011) and Murray-Harvey et al. (2010) call such strategies institutional coping mechanism, where teachers turn to formal structures within a school in order to cope with their work situations.

\subsubsection{Working overtime and modifying the conception of work}

In order to cope with a heavy workload, most teachers use their spare time, weekends and evenings to meet deadlines and finish school work, as illustrated by the extracts below:

\footnotetext{
'...OBE requires that you do a lot of admin (paper work) so you end up rushing the children so that you can complete admin records. There you actually spend less time with the children... then at times you have to do admin after hours, you do some on weekends, evenings and at times during holidays...' (Tr3).

'...I use my spare time; I sacrifice my own time to do the work... at times I swap the subjects because the load of subjects is not the same. For instance Arts and Culture and Maths... Arts and Culture is one lesson a week for Maths you need more time for children to understand. In that case I can take time from other subjects and give it to Maths in order to help the learners...' (Tr6).

'...I have to stretch myself. That means I have to work extra hours, three times a week I wake up at night to do school work. I can't type very fast using the computer. So I need to work more hours on my work on the computer. They need to find a typist who can do all these things and I spend most of my time with the learners...' (Tr7).
}

For these participants, there is a need to work extra hours in order to cope with their work. At times teachers, as street-level bureaucrats, cope with work pressure by modifying their conception of work (Lipsky, 1980, 143). He says that street-level bureaucrats cope with job stresses by modifying their conception of work and their conception of clientele to be served, as illustrated by Tr20:

'Teaching is now part of my life. I don't even feel burdened even if I am doing it at home or during holidays or even picnics. I join family time with work life' (Tr20).

Our data sets indicate that teachers work overtime and modify the conception of work in order to plan and prepare for lessons and to mark, even at home. This is termed a professional coping mechanism (Brackenreed 2011; Johnsson 2012). However Sharplin et al. (2011) observe that professional coping mechanisms come with experience. The conception of work is altered to extend it beyond the classroom and normal working hours. 


\subsubsection{Private goal definition}

Another way in which teachers modify their conception of work is by focusing on a few aspects of their job. Some teachers complained about the discipline among the learners. They said that if you want to focus on 'perfection' from our learners you will never find it (Tr9). They argue that it is better to focus on your subject. Lipsky calls this coping mechanism 'private goal definition' $(1980,145)$. He says teachers are oriented toward classroom control or toward cognitive and personality development. It is, however, important to note that a lack of discipline may hinder proper learning in class, too.

\subsubsection{Withdrawal from stressful situations}

One respondent said that coping with work demands is very difficult. For this reason, this respondent is thinking about quitting the job next year.

\footnotetext{
'...I sleep very late, I come here very tired. I can't manage when I am tired. That's the reason I want to resign. I cry
} every day, I teach seven learning areas, some of which I don't know much about...' (Tr17).

Lipsky says that 'idealist young teachers quit either because they cannot tolerate the pettiness of their supervisors or they have an inability to teach as they would like or were trained to teach' $(1980,143)$. Lipsky notes that street-level bureaucrats show different withdrawal attitudes. Some of the withdrawal manifestations among street-level bureaucrats are absenteeism, high turnover and general slowdowns. This particular school has been losing at least five teachers per year for the past two years. Although only one teacher in our study reported that he was quitting the job because he could not cope, academic literature is filled with such cases (Richards 2012; Sharplin et al., 2011). In some cases, withdrawal coping mechanism does not result in quitting but teachers withdraw psychologically by maintaining a low profile or taking time off (Hawk and Martin 2011; Sharplin et al., 2011; Timperley and Robinson 2000).

\section{Discussion and Conclusions}

First, our study sought to explore the factors that cause teachers to devise coping mechanisms during curriculum policy implementation. Our data suggest that teachers are pressurised into coping strategies due to three broad factors, which are the scarcity of resources, clarity of goals and performance measures, and relations with non-voluntary clients. Scarcity of resources was deemed to be one of the major factors that presented undue pressure on teachers. These resources were both practical and theoretical resources. Teaching and learning materials were so scarce that teachers had to implement curriculum policy with such limited resources. Teachers were also overwhelmed by the number of learners which made the maintenance of classroom discipline a challenge. Limited personal resources among them were also identified as limited experience by some educators. Time, as a resource, was always in short supply, as shown in our findings. It is apparent that scarcity of resources hinders policy implementation and forces teachers to devise coping mechanisms. What is the nature of such coping mechanisms?

The results of our study indicate that although respondents are faced with similar stressors during the enactment of policy, they devise different coping mechanisms. Although different scholars have classified coping mechanisms into classes such as personal coping mechanisms, professional coping mechanisms, social coping mechanisms and institutional coping mechanism (Murray-Harvey et al., 2010), our characterisation of coping mechanisms follows Lipsky's conceptualisation of such mechanisms. Consequently, our conceptualisation of coping mechanisms falls into these classes; 'creaming', 'rubber stamping', referrals, working overtime and modifying the conception of work, private goal definition, and withdrawal. With regard to creaming, teachers focus on learners that they think have the potential to do well, or those who were willing to co-operate, and gave little attention to those who lacked motivation and are confrontational towards the teachers. These findings confirm previous findings in the academic literature, where respondents resorted to non-confrontational coping devices in order to cope with their work situation, by focusing attention on clients who reciprocated their efforts (Richards 2012; Brackenreed 2011).

Our study has gone some way towards enhancing our understanding of the causes of coping mechanisms among teachers in the South African context. Our observation has crucial implications for teachers, school management teams and policy-makers. This work has revealed that, regardless of social or economic context, teachers will often face stress during curriculum enactment, which will call for coping mechanisms. In some cases, such coping mechanisms are devised to attain organisational goals, but in most cases they are designed to make working conditions comfortable. The 
resultant coping mechanisms have important implications for educational policy implementation. The school management teams have a special role in providing adequate resources, where possible.

In terms of different coping strategies adopted by teachers, our findings contribute to the knowledge about positive and negative coping mechanisms adopted by teachers. It is apparent that curriculum policy outcomes might be a product of coping mechanism of teachers. Educational managers should encourage coping mechanisms that are designed to attain policy goals under prevailing challenges that teachers face. Coping strategies that are meant to make the work of teachers more comfortable at the expense of policy goals should be discouraged.

Horizontal interactions (between colleagues) and vertical interactions (between teachers and line managers), which our study did not explore, could be another source of stress during the enactment of curriculum policy. Further research in line with this potential source of stress might extend our scope of understanding sources of stress. In spite of this, we believe that our work could be the a starting point for more elaborate studies to understand the causes and nature of coping mechanisms devised during curriculum policy enactment in South African schools, in particular, and in the developing world, in general.

\section{References}

Aldridge, J. M., Rüdiger C. Laugksch, Seopa, M. A. \& Frasera, B. J 2006. Development and Validation of an Instrument to Monitor the Implementation of Outcomes-Based Learning Environments in Science Classrooms in South Africa. International Journal of Science Education 28, 45-70.

Arnould, E. J. \& Wallendorf, M. 1994. Market-oriented ethnography: interpretation building and marketing strategy formulation. Journal of Marketing Research, 31, 484-504.

Bergen, A. \& While, A. 2005. 'Implementation Deficit' and 'Street-level Bureaucracy': policy, practice and change in the development of community nursing issues. Health and Social Care in the Community, 13, 1 - 10.

Brackenreed, D. 2011. Inclusive education: Identifying teachers' strategies for coping with perceived stressors in inclusive classrooms. Canadian Journal of Educational Administration and Policy, 122, 1 - 36.

Butler, R. 2007. Teachers' achievement goal orientations and associations with teachers' help seeking: examination of a novel approach to teacher motivation. Journal of Educational Psychology, 99, 241-252.

Chitakunye, P. 2012. 'Recovering children's voices in consumer research'. Qualitative Market Research: An International Journal, 15, $206-224$.

Chitakunye, P. \& Maclaran, P. 2014. Materiality and family consumption: The role of the television in changing mealtime rituals. Consumption Markets and Culture, 17, 50 - 70.

Crossman, A. \& Harris, P. 2006. Job Satisfaction of Secondary School Teachers. Educational Management Administration \& Leadership, $34,29-46$.

Department of Education 2003. Systematic Evaluation: Foundation Phase Main Stream, Pietermaritzburg, Department of Basic Education.

Deventer, K. V. 2009. Perspectives of Teachers on the Implementation of Life Orientation in Grades R-11 from Selected Western Cape schools. South African Journal of Education, 29, 127-145.

Fantilli, R. D. \& Mcdougall, D. E. 2009. A study of novice teachers: Challenges and supports in the first years. Teaching and Teacher, Master of Home Science, 814 - 825.

Gorman, G. E. \& Clayton, P. 2005. Qualitative research for the information professional A practical handbook, London, Facet Publishing.

Grimaldi, E. 2012. Analysing policy in the context(s) of practice: a theoretical puzzle. Journal of Education Policy, 27, 445-465.

Harden, R. M. 2002. Learning Outcomes and Instructional Objectives: is there a difference? Medical Teacher, 24, 151-155.

Hawk, N. \& Martin, B. 2011. Understanding and Reducing Stress in the Superintendency Educational Management Administration \& Leadership 39, 364 - 389.

Johnsson, M. 2012. Street-level bureaucracy, professionalism, and war. Understanding the formation of force conduct in contemporary counterinsurgency operations. Higher Education Seminar.

Keddie, A. 2013. Thriving amid the performative demands of the contemporary audit culture: a matter of school context. Journal of Education Policy, 28, 750-766.

Lipsky, M. 1980. Street-level Bureaucracy: Dilemmas of the individual in public services. New York, Russell Sage Foundation.

Lipsky, M. 2010. Street-level Bureaucracy: Dilemmas of the individual in public service, 30th Anivesary Expanded Edition. New York, Russell Sage Foundation.

Magashoa T. 2013. The Role of Members of School Management Teams in Curriculum implementation and management: A Case Study of Selected School s in the Gauteng Province (Republic of South Africa). Mediterranean Journal of Social Sciences, 4 (14) 135 140.

Makeleni, N., \& Sethusha, M. J. 2014. The experiences of Foundation Phase Teachers in implementing the curriculum. Mediterranean Journal of Social Sciences 5 (2) $103-109$.

Mansfield, C. F., Beltman, S., Price, A. \& Mcconney, A. 2012. 'Don't sweat the small stuff:' Understanding teacher resilience at the chalkface. Teaching and Teacher Education, 28, 357-367. 
Maphalala, M. C. 2014. The Manifestation of Occupational Stress in the Teaching Profession: The Unheeded Voices of Teachers, Mediterranean Journal of Social Sciences, 4 (1) $77-88$.

Murray-Harvey, R., Slee, P. T., Lawson, M. J., Silins, H., Banfield, G. \& Russell, A. 2000. Under Stress: The concerns and coping strategies of teacher education students. European Journal of Teacher Education, 23, 19-35.

Nayak, J. 2008. Factors Influencing Stress and Coping Strategies Among The Degree College Teachers of Dharwad City, Karnataka Master of Home Science University of Agricultural Sciences.

Parsons, W. 1995. Public Policy: An introduction to the theory and practice of policy analysis, London, Edward Edgar.

Reames, E. H., KOCHAN, F. K. \& ZHU, L. 2013. Factors influencing principals' retirement decisions: a southern US perspective. Educational Management Administration \& Leadership online version http://ema.sagepub.com/content/early/2013/11/18/ 1741143213499254.

Richards, J. 2012. Teacher Stress and Coping Strategies: A National Snapshot. The Educational Forum, 76, 299-316.

Sharplin, E., O'Neill, M. \& Chapman, A. 2011. Coping strategies for adaptation to new teacher appointments: Intervention for retention. Teaching and Teacher Education, 27, 136-146.

Smith, K. 2012. Coping Mechanisms and Level of Occupational Stress Among Agriculture Teachers and other Teaching Populations Mater of Science, Utah State University.

Spiggle, S. 1994. Analysis and interpretation of qualitative data in consumer research. Journal of Consumer Research, 21, $491-503$.

Sprenger, J. 2011. Stress and Coping Behaviours among Primary School Teachers. Master of Arts, East Carolina University.

Strauss, A. \& Corbin, J. 1998. Basics of Qualitative Research: Techniques and Procedures for Developing Grounded Theory, Beverly Hills, CA, Sage.

Taylor, I. 2007 Discretion and Control in Education: The Teacher as Street-level Bureaucrat Educational Management Administration \& Leadership 35, 555-572.

Thomson, P. 2008. Answering back to policy? Headteachers' stress and the logic of the sympathetic interview. Journal of Education Policy, 23, 649-667.

Timperley, H. \& Robinson, V. 2000. Workload and the Professional Culture of Teachers. Educational Management Administration \& Leadership, 28, 47 - 62.

Tummers, L. \& Bekkers, V. 2013. Policy Implementation, Street-Level Bureaucracy, and The Importance of Discretion. Public Management Review, http://dx.doi.org/10.1080/14719037.2013.841978.

Tummers, L. G. \& Bekkers, V. (2014) Policy implementation, street-level bureaucracy and the importance of discretion. Public Management Review.

Yeung, S. Y. S. 2012. Policy in Hong Kong from the Perspective of Curriculum Leaders. A School Evaluation Policy with a Dual Character: Evaluating the School Evaluation. Educational Management Administration \& Leadership 40. 